upon the disc that would either conduct or break the current. The apparatus when complete acted perfectly, and the minutest current could be detected. Sometimes I used the battery with a single cell, sometimes with more than a single cell, while, as a general rule, I used the whole power of cells, twenty-four in number. When all was in order and the battery in action the platinum probe was brought into direct contact with the platinum disc, and the current was proved by the deflection of the needle on the galvanometer. After this, the needle being steadied and set, a piece of some thin membrane was laid on the platinum disc, and its conduction or resisting power tested with the results to be described.

Dura mater.-A disc was cut from the dura mater of a dead sheep, and, after being thoronghly cleaned, was laid on the platinum disc. The probe like end of the conductor from the battery was then pressed upon it when the current was found to be completely intercepted. The insulation was, in fact, perfect. A piece of membrane covering the spinal cord at its upper part, stripped off and carefully cleaned, was laid on the platinum disc, and the probe end of the conductor was put upon it. It resisted the current as effectively as a layer of indiarubber or guttapercha or a fine slice of fatty tissue could have done.

Periosteal membrane.-From off a bone a bit of periosteum detached, cleaned, and laid on the platinum plate insulated perfectly.

Pericardial membrane.-This membrane was tested in the most careful manner and yielded the same result.

Endocardial membrane.-There was more trouble with endocardial membrane than with pericardial, for the structure is very fine and strongly adherent to the underlying substance. But when cleanly dissected out it was found to be as perfect an insulator as the pericardium, so that the heart structure proper is apparently enclosed in two layers of insulating membrane. The endocardial lining of the arteries showed the same character; the valves of the heart cut out entire did not absolutely insulate, but the membrane covering them on either side did.

Peritoneal membrane.-Portions of peritoneal membrane were taken from various parts-from the liver, from the spleen, from the intestine, and from the bladder. When the membrane was derived from any of those sources and scrupulously cleaned and spread out on the platinum disc it resisted just as the other membrane had done and proved itself an insulator.

Capsule of the kidney.-The readiness with which the capsule of the kidney can be detached renders it a good specimen for experiment, and it was freely used. It proved to be a perfect insulator, and we may consider that the kidney as it swings in its place is completely insulated.

Lining membrane of an egg.--The thin lining membrane of an egg detached from the inside of the shell, when tested, showed the same insulation.

It was a question whether mucous membrane in the same manner as serous membrane resists the current. To test this fact mucous membrane was taken from the side of the tongue of a sheep, from the lining of the intestinal canal, and from the lining of the trachea. The membrane had to be carefully cleaned, with the greatest attention to detail, and when it was laid out in its pure character of membrane it also insulated.

In the above, physiological observations have alone been named, but there are pathological ones connected with the subject of equal moment. The absorption of water by membrane, water being a conductor, may interfere with insulation in the case of dropsies, and some deposits may also interfere. But these and other points remain for investigation.

Society For IMPRoving THE CoNDITION OF THE LABOURING CLASSES. - The fifty-second annual meeting of the Society for Improving the Condition of the Labouring Classes was held at No. 8, Southampton-row on June 26th, the Right Hon. Evelyn Ashley presiding. The report showed that $£ 1000$ of the loans raised for the purposes of the society's work had been paid off during 1895 and the early part of the present year. The committee were at present considering the establishment of a boarding house for young men. During 1895 there was an average population of 573 in the society's buildings, and there were five deaths. The income exceeded the expenditure by $£ 960$.

\section{A THERAPEUTICAL BLUNDER-BEEF AND MALT WINE.}

BY FREDERIC C. COLEY, M.D. DURH.,

PHYSICIAY TO THE HOSPITAL FOR CHLLDREN, NEWCASTLEUPON-TYNE, AYD TO THE NORTHERN COUNTIRS HOSPITAL FOR DISEASES OF THE GHEST.

THERE are various preparations on the market professing to be made up of extract of beef, extract of malt, and port wine. If this combination were believed in only by the uneducated public one need not be surprised. It is just the sort of therapeutic blunderbuss which might be expected to take the fancy of those who do not know better; but when we find members of the medical profession recommending such a conglomeration it is time to draw attention to the absurdity of it. It is, in fact, difficult to imagine a more thoroughly unscientific combination than the one in question. Let us consider the ingredients separately and see whether they are well calculated to act together.

Extract of beef we all know is not food. Liebig himself proclaimed that. It has its use however. First and foremost, it is valuable because of its meaty flavour, on account of which many patients can take with it bread or lentil flour, \&c., which would otherwise be unacceptable. It is also a harmless stimulant. Lastly, people who cannot take tea or coffee at supper time for fear of insomnia, and are liable to biliousness when they substitute cocoa, often find extract of beef (or some similar preparation) very useful because it decidedly favours sleep. To combine such a preparation with port wine shows a complete ignorance of its real uses. The slight stimulating effect of the very small quantity of the extract contained in an ordinary dose of the wine would be wholly. inappreciable in the presence of the alcohol. It is plain that the only conceivable motive for such a combination must be the erroneous notion that extract of beef is capable of doing duty as a food.

Extract of malt is a valuable preparation, but when I prescribe it I like to know how much of it my patient will get. I doubt very much whether an adequate dose of it can be contained in a wineglassful of the very mobile fluid which is sold as beef and malt wine. Nor do I see any reason to suppose that its powers for good are likely to be improved by mixing it with an unknown proportion of an alcoholic liquid.

Lastly, we have to consider the port wine. I shall not here express any opinion as to the therapeutic value of genuine port, but I believe that those of $\mathrm{my}$ professional brethren who have the strongest faith in its virtues most earnestly insist on the necessity of securing the real fermented juice of the grape. It is notorious that much spurious wine is in the market, and that it is extremely difficult, with the greatest care, to obtain an undoubtedly genuine article even when a high price is not grudged. I do not know where the makers of beef and malt wine get their supplies, so I am not in a position to make any positive statement about the genuineness (or otherwise) of their "vintage," but I may mention some facts which appear to me to bear on the probabilities of the subject. The proprietors of the best known (because most extensively puffed) beef and malt wine have twice sent out circulars to the medical profession offering debentures at a high rate of interest. This was done avowedly with the design of interesting the profession in the sale of the article. I have myself received from the same company at different times more than a dozen sample bottles of their wine, and I have no reason to suppose that I have been more liberally treated than the rest of my brethren. I simply ask, what must be the profit on the sale when it is able to cover the cost of this enormous distribution of samples and of the profuse advertising which is done, and then leave enough to pay an exceptionally high interest on the debentures and dividends to the shareholders presumably at a still bigher rate? I suggest no inference from these facts, but "I speak as unto wise men; judge ye what I say."

If we beliere that any of cur patients are likely to derive benefit from malt extract by all means let us prescribe it- 
in doses such as we know to be adequate. If we are disposed to use extract of beef (or any similar preparation ${ }^{2}$ ) let us remember that it is not a food and that it will therefore 'be worse than useless if it is so combined as to make it incapable of serving the only purposes for which it is really adapted. It must be agreed that we are recommending a very doubtful investment of money when we advise a patient to bay a bottle containing an unknown quantity of extract of beef and extract of malt dissolved in a liquid of problematical composition called port wine. From the $£ s$. $d$. point of view the debentures above mentioned are a much better speculation. But they are offered to the medical man vather than to the patient.

Newcastle-on-Tyne.

\section{ALBUMOSURIA IN CHRONIC KIDNEY DISEASE. ${ }^{2}$}

By A. LOCKHART GILLESPIE, M.D., F.R.C.P. EDIN., MEDICAL REGISTRAR, EDINBURGE ROYAL INFTRMARY.

THE condition of peptonuria, as first described by Hofmeister, has long been recognised to be really albumosuria in a great number of cases, with or without the presence of peptone, properly so called, in addition. Hitherto the presence of these bodies in the urine has been regarded, irst, as evidence of suppuration in the body, wherever situated, if the conditions were favourable to the absorption by the blood of the lower proteids of the pus, or, in the second place, as evidence of infective disease, especially if accompanied by pyrexia. For example, von Jaksch found peptone in the urine in cases of pneumonia during the stage of softening, in purulent meningitis, in phthisis with suppuration, and in the latter stages of severe scurvy. Maixner and Pacanowski bave shown that it may occur in ulceration of the intestine, while according to Fischel it is the normal concomitant of the puerperal state. Shortly, peptonuria and some forms of albumosuria occur when there is either well-marked suppuration or rapid destruction of proteid material in the body. The appearance of albumoses in the urine during the course of fevers is, of course, due to the same cause-the rapid destruction of proteids. Another explanation of the appearance of these bodies in the urine is afforded by the fact that many micro-organisms have the power of changing albumin and globulin into proteoses and peptones. Any process in the body which is due to the presence of such organisms must throw into the blood stream the products of their action on albumins, and these products will be at once excreted by the kidneys.

Albumosuria, strictly so called, has been recognised by many observers in osteomalacia, dermatitis, mental derangement, measles, and scarlet fever, but competent authorities, such as Osler and Roberts, doubt if the occurrence of albumose in the urine is of much clinical significance. The presence, however, of any form of proteid in the urine can never be regarded as a light matter, whether the proteid discovered be passed in that form or be changed in its transit from the kidney. In this connexion it is right to state here that proteoses or peptones in the urine may be either secreted as such by the kidney, or, secreted as albumin by that organ, may become altered during their passage down the urinary tract by bacterial action or by digestion. In either case the kidney must be at fault. It is hardly necessary to add that all testing for albumoses or peptones must be done at unce and on a perfectly fresh specimen of urine. A trace of albumose in a urine containing a considerable amount of albumin or globulin, especially if the urine be slightly stale, means nothing. Much albumose or peptone in an absolutely fresh urine with or without albumin signifies their excretion by the kidney. It is impossible that digestion can go on in the bladder or after the urine is passed so quickly, whether it is due to bacterial action or to unorganised fermentation, as to convert more than an infinitesimal portion of albumin into proteoses or peptones. In those cases in which no coagulable proteid can be detected the lower proteids present must be excreted

1 Dr. Coley refers exclusirely here, we may take it, to those preparations which contain simply the constituents of beef dissolved out on extraction with bot vater.-ED. L.

2 The aldalyes fol this vaper were performed in the Research Laboratory of the kral College of Physicinns of Edinburgh. in propria person $\hat{a}$ by the kidney. This must be so because in digestion experiments, or in experiments on the digestive action of micro-organisms, a long time invariably elapses before all the coagulable proteid in the test solution is acted on. Several different forms of albumose may be found in the urine, but of these heteroalbumose (Bence-Jones's albumin) and deutero-albumose are the most common. Dysalbumose may also be present, and proto-albumose if carefully looked for, although Dr. Sidney Martin, writing on this subject in the last edition of "Quain's Dictionary of Medicine," states that proto-albumose has never been obtained from the urine. Dr. Martin sums up his article as follows: "According to our present knowledge it may be said that the chief clinical significance of a large amount of peptone or albumose in the urine is an extensive cell (and proteid) disintegration in the body, in many cases indicating pus formation."

In the Edinburgh Hospital Reports, vol. ii., I published the results of analyses of the urine in a case of chronic nephritis. The patient, who was five years of age, was under the care of Dr. A. S. Cumming and suffered from all the symptoms of chronic Bright's disease. Owing to the urine yielding some unusual reactions when tested for albumin, $\mathrm{Dr}$. Cumming asked me to undertake its analysis. There is no need here to reproduce any of the facts of this case which were observed, save to mention that the amount of deuteroalbumose recovered was always greater than that of the proto-albumose. This latter was certainly present. The albumoses reached on one occasion the very considerable amount of 0.247 per cent, the coagulable proteid for the same day being 0.331 per cent. After about a month albumoses disappeared from the urine, shortly after tincture of strophanthus had been exhibited. As they disappeared the amount of serum-globulin in the urine became larger. Dr. Halliburton has objected ${ }^{3}$ to the use of Devoto's method of separating albumoses from fluids which also contain coagulable proteids, referring especially to some analyses which I had made of the fluids from various serous effusions. In this case, however, such criticism is inapplicable, as the urine gave the tests for albumoses before boiling with acetic acid, and further the method which he now decries, although recommended in his text-book on "Pathological Chemistry," failed to show the presence of any of the lower proteids after a certain date, even when treated in identically the same way and although coagulable proteids could still be separated out. If the albumoses present or recovered by this method are small in amount it may be doubtful whether they were originally in the urine or were produced in the course of the ana?ysis; when they are present in large quantity Devoto's method is by far the best. One precaution should be taken, however, and that is not to add the acetic acid until the urine has been brought to the boil, and then at once to let it cool. In this way there is very little chance of the acid modifying the nature of the proteids present.

In June, 1895, I was asked by a woman to prescribe for symptoms of congestion of the liver. She was about fiftysix years of age and complained of nausea after food, headache, and a quivering movement of objects before her eyes. On examination it was found that pressure over the liver caused pain, the face was puffy, the pulse inelastic, the heart sounds normal, the sight, especially of the left eye, was weak, and insomnia was of frequent occurrence. From the appearance of the face some affection of the kidneys suggested itself to me, but examination of the urine failed to reveal the presence of albumin; there were no tube casts and the specific gravity was 1018. Trea'ment was therefore directed toward improvement of the action of the liver, especially as the patient had already suffered from gout, whilst chloralamide was given for the sleeplessness. A fortnight later her condition was much improved, but she was rery lethargic and the eyesight was still defective. I sent her to Dr. George Mackay, who reported the presence of hæmorrbagic retinitis in the left eye and inquired especially whether there was no albuminuria. A further examination of the urine yielded the following interesting particulars. Its specific gravity was 1022 and it contained 9 per cent. of urea, the patient being on a milk diet. Cold nitric acid gave no precipitate, showing that there was no albumin or hetero- and protoalbumose. Picric acid yielded a cloud disappearing on the application of heat-i.e., albumose or peptone. Saturation with ammonium sulphate caused a precipitate soluble in water. 